\title{
Use and misuse of the seas around the Galápagos Archipelago
}

\author{
Godfrey Merlen
}

\begin{abstract}
Although the Galápagos Islands were first colonized over 160 years ago, the major impact on the marine resources by local fishermen has occurred only during the last 40-45 years. During this period, and especially more recently, a lack of attention to the largely uncontrolled fishery has led to confusion, a conflict of interests, and a series of inapplicable laws and regulations. Changing markets, exploding human populations, and a new approach to marine resource exploitation, with minimum investment and maximum expectation, has led to a chaotic situation in which neither the fishermen nor the Galapagos National Park will ultimately benefit.
\end{abstract}

William Beebe, scientist, inventor and explorer, visited the Galápagos Islands on two occasions. His first visit, in 1923, resulted in his account titled Galápagos: World's End. Perhaps, in retrospect, it should have been called 'The End of Galápagos's World,' because this volume helped to excite the imagination of hard-pressed Norwegians, who left their homeland in several expeditions to set up fish-canning operations in the Galápagos Islands in the middle and late 1920s. These attempts failed because of lack of freshwater and leadership, but they helped raise interest and curiosity about this oceanic archipelago. Up until the Second World War, four- or sixman double-ended rowing boats with auxiliary sails were used in bottom-fishing activities, but their dependence on oars against oceanic currents in the often windless weather, must have limited their effectiveness and their penetration into the Archipelago. The fishermen operated out of Puerto Baquerizo Moreno on San Cristobal Island, the easternmost island, where by far the majority of the people lived (Figure 1). However, they did reach at least as far as Santa Cruz Island. They used a method of preserving their catch, perhaps introduced by the Norwegians, which is used to this day, known as 'seco-salado.' This involves opening the fish, salting and drying them on the hot, bare coastal lava fields to produce 'bacalao'. For many years the fishery was directed at one species, the serranid Mycteroperca olfax. Later, when more boats were involved and the market would stand it, many other species of serranid were used. Other families, including Lutjanids (snappers), Labrids (wrasses), Scorpaenids (scorpion fish), and Carangids (jacks) also became acceptable. The bacalao was exported to mainland Ecuador and was very popular as an ingredient in the grain-based soup known as 'fanesca,' produced uniquely during Easter week. Occasionally sail-powered 'balandras' came from the mainland to fish. At the same time, the first of the North American tuna vessels were seen in the Islands. They fished for yellow fin tuna Thumnus albacares with poles and barbless hooks, long before the advent of the purse seine net, the use of which, however, would eventually be adopted.

During the Second World War, the construction and operation of the US military base at Baltra (one of the central islands), occupied several thousand people and provided a ready market for fresh fish. But more than the market, it was probably the arrival of a war-generated technology, with diesel engines, tools, equipment, and the movement of men, that set the pace for the new generation of fishermen. A new attempt was made to set up a processing plant, this time a massive 


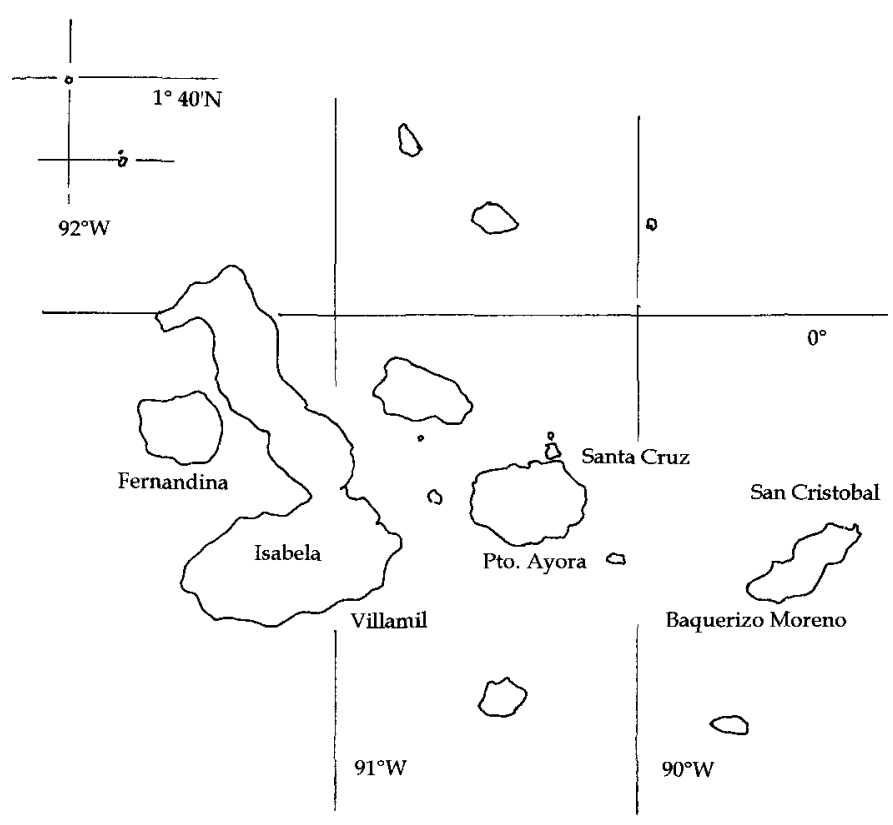

Figure 1. Map of the Galápagos, showing the three principal islands with fishing operations and their respective ports. As the lucrative fisheries for sea cucumbers and lobsters are based in the western islands of Isabela and Fernandina, much attention has been given to the small port of Villamil. The pristine island of Fernandina, once a remote region of the Archipelago, is now frequently visited by the uncontrolled, highly mobile fishermen. freezer station at Puerto Baquerizo Moreno. Lack of administrative ability seems to have condemned this enterprise, but not before a number of diesel-powered boats had been brought in. The plant ceased operating in the mid-1950s, but by then many privately owned boats were operating. The introduction of the inboard diesel engine brought much more mobility, and the fleet ranged more widely. Longtime residents remember that boats were reaching the extremities of the Archipelago, with the fleet stabilizing between 20 and 30 vessels, ranging in size from 5 to $10 \mathrm{~m}$ and working from the islands of San Cristobal and Santa Cruz. This group of people and their bacalao fishing constituted the 'traditional artisanal' fishery of Galápagos, which continues to this day. The boats are owned by strongly bonded families and a survey in 1981 (Reck, 1983) revealed that 80 per cent of the fishermen interviewed on San Cristobal were born on the island and only 5 per cent had no relatives within the industry. It is refreshing to talk with these people and hear their descriptions of the islands and the once abundant fish and lobsters: bays alive with mullet, rocks so crowded with lobsters in knee-deep water that their radiating antennae resembled masses of flowers. The people lived on the islands and knew the waters around them intimately.

However, with improved transport, increasing world-wide affluence, the demand for luxury seafoods, and the development of technology, the Islands became more accessible and easier to exploit. Spiny lobsters (Panulirus spp.) had been eaten by the local population for many years as a subsistence food, but, because there was no local market and no system to preserve the tails for the export trade, exploitation remained at a low level. In the 1960 s and 1970 s vessels with large-capacity freezers arrived from mainland Ecuador and changed this. Eventually, four ships $23-30 \mathrm{~m}$ long and each carrying 12-16 divers (the extremely rough sea floor and the curiosity of sea lions had always prohibited the use of lobster traps), were operating archipelago-wide. The divers worked for many hours a day, using surface-delivered compressed air and reaching depths of up to $25 \mathrm{~m}$. At one time, lobster tails from Galápagos accounted for up to two-thirds of Ecuador's export of this product. Thus outside investors made their first successful invasion into Galápagos marine resources. The divers, most of them 'outsiders', became more familiar with the seas of the is- 
lands than the local fishermen. During this time, from the 1960 s to the mid-1970s, several large, foreign-registered vessels entered Galápagos waters and bought catches from local fishing boats. This was started by two US-flagged boats, the Lucy and the Jane. They were followed by three Panamanian-registered vessels. Two, the Kodiak ${ }^{*}$ and the Wallenbusch, appear to have been dedicated to fish products, but the Panamanian-registered Chikutzen Maru bought anything it could obtain: goat meat, marine turtles (Chelonia mydas), and all kinds of fish at one sucre per pound (the sucre is the local currency; in 1970, one and a half sucres would buy 20 cigarettes). Local fishermen grasped at this opportunity to pay off debts on their boats. This market was terminated by law in 1974, along with the export of lobster from Ecuador, but, unfortunately, it appears to have encouraged the get-rich-quick, short-sighted view, which has dominated the fishery scene since then.

Although a plan was put forward for marine conservation in 1975 (Wellington, 1975), it was complicated by serious differences of opinion as to who should have the administrative power over the marine environment, even though many governmental bodies recognized that a rampant fishery could damage the marine environment, upon which so much of the biology of Galápagos depends. While these bureaucratic obstacles continued, the situation in Galápagos was becoming more difficult to control. For one thing, the human population exploded (and is still growing): 450 people lived in the Archipelago in 1905; 800 in $1949 ; 3500$ in 1971; 9785 in 1990. This increase was due to a number of factors, including the rapid growth of the service industries, which centre on tourism, and the lure of this fastgrowing business. The growth of tourism, which started in an organized way in 1969, complicated enormously the economic interests of the various groups of people. There appear to be three divergent opinions concerning the marine environment, with some people trying to embrace more than one of them. There are pure conservationists, who

* The spelling of the boats referred to is uncertain.

(c) 1995 FFPS, Oryx, Vol 29, No 2 view all human activity as injurious to the natural system. There is the tourist industry, which perhaps hides a little behind the freshly-coined 'ecotourism,' but nevertheless is generally concerned about the well-being of the Islands, if for none other than purely economic reasons. Finally, there is the fishing community, which, because it is the activity that depends upon direct extraction of resources and operates under minimum control, is regarded by some as the villain. The bottom line, however, is that the economic interests believe they have the right to make a living from the Islands whatever the consequences.

The ban on the export of lobster tails after suspected overexploitation and the prohibition on foreign vessels entering the Islands in 1974 had several results. One was that fishing activities became decentralized, which, coupled with the cessation of scientific investigation in 1981, rendered it impossible to estimate reliable catch figures. This chaotic fishery, in turn, resulted in panic measures by the central government, such as total prohibition in the face of overexploitation. It also had another effect. As the large boats disappeared (the last lobster vessel, El Salvador, left in the early 1980s), many of the previously employed fishermen started their own small operations, using dinghies and outboard engines. Because many of them had originated on the coastal mainland, their intimate knowledge of the Archipelago, gained through their experiences as divers, soon became widespread. This started an avalanche of low-investment operators who brought their own type of law and their own type of boat, the 'fibra' - slim, extremely fast, seaworthy and up to $6 \mathrm{~m}$ long.

Many of the launch owners have no concept of Galápagos except to make quick profits and pay off often inadvisable bank loans. The launches operate not only from Puerto Baquerizo Moreno, San Cristobal Island, and Puerto Ayora, Santa Cruz Island, but also from Puerto Villamil, a small village on the south coast of Isabela. Their high mobility made access to the western fishing area easy and these boats have entered all fields of marine exploitation: bottom fishing; fishing with harpoons (prohibited by law); fishing with 
monofilament nets (prohibited by law); fishing for shellfish (Murex and Fasciolaria spp.); fishing for lobster at night (prohibited by law); fishing for lobster with compressed air.

The chaotic resurgence of the lobster industry by small independent operators led to a severe depletion in the populations of both species of spiny lobster, Panulirus penicillatus and $P$. gracilis. The harvesting of undersized lobsters (less than $25 \mathrm{~cm}$ total length) and gravid females (prohibited by law) certainly helped in this decline. In desperation, the central government in 1992 imposed a total ban on harvesting of lobsters until the end of the century.

However, these boats are ready for any other opportunity that may present itself. The casting around for new opportunities is not restricted to these numerous small operators. The traditional bacalao fishermen are encountering economic problems, because the sale of salted fish is declining with fresh fish being bought from mainland suppliers, including imports from Peru. This is complicated by the lack of willingness to invest more money in the fishery and a reluctance to reduce the price of their product. Also there does not seem to be much opportunity to expand the bottom fishery; Reck (1983) estimated that an increase in fishing pressure would exceed the sustainable yield. The bacalao has always been a seasonal fishery, starting in September and ending before Easter. If the fish cannot be sold, the families face a hard time, because the island economy is now firmly based on the US dollar (because of the tourist trade) and fish prices are based on a lower-valued local currency.

In addition, Japanese and Korean influence and markets have been present for many years in Ecuador, and in recent years they have compounded the problems in Galápagos. The latest activities put in grave danger some of the unique wildlife communities found within the Archipelago.

The first industry with a truly Asian character was the trade in shark fins. There has been an active movement of this commodity worldwide for many years. Large vessels, mostly Japanese long-liners, have been common on the periphery of the Galápagos for decades.
Reports of the Inter-American Tropical Tuna Commission bear witness to this major highseas fishery in the tropical Eastern Pacific. The infamous Chikuzen Maru was perhaps the first vessel to bring this trade within the Islands. I observed the rows of drying fins over its decks in 1970. The killing of sharks for their fins is now an island industry. The small space occupied by the fins, the lack of the need to invest in equipment to preserve them, and the price paid make them an attractive item. Moreover, the geographical position of the Islands, which obstruct several major oceanic currents, sets up conditions in which sharks abound. This fishery was banned in 1989 after it was discovered that sea lions were being killed as bait and set in nets to attract sharks. Nets have often been found extremely close to shore. The fishermen, who do not have a market for the meat and who do not wish to invest in buying freezers to preserve it, cut off the fins and discard the bodies. Although fishing for sharks is banned near the Galápagos Islands, it is permitted 80 nautical miles outside the Archipelago, as long as the whole animal is used. Local fishermen regard this rule as discriminating against them and the practice of gathering fins continues. To add to the problem, they use highly indiscriminate nets, whereas the method of fishing on the highseas is the long-line. This operation comes into direct conflict with SCUBA-diving tourism, which is a fast-growing business.

The second trade, which started in mainland Ecuador in 1988, centres on a species of sea cucumber, Isostichopus fuscus, which is eaten as a luxury food in parts of Asia. The centres of distribution for processed sea cucumbers are Singapore, Taiwan, and Hong Kong (Sommerville, 1993). In Japan, sea cucumbers are eaten raw, which makes it unlikely that Japan would provide a market for processed animals from the Galápagos. Again, this is not a new trade by world standards, but its uncontrolled spread to the Galápagos in 1992 represents a serious threat. The sea cucumbers, slow-moving holothurians, live in shallow, quiet waters and are easily harvested. Unfortunately, processing them involves cooking and drying. On the continental shelf 
A sea-cucumber-fishermen's camp (Charles Darwin Research Station).

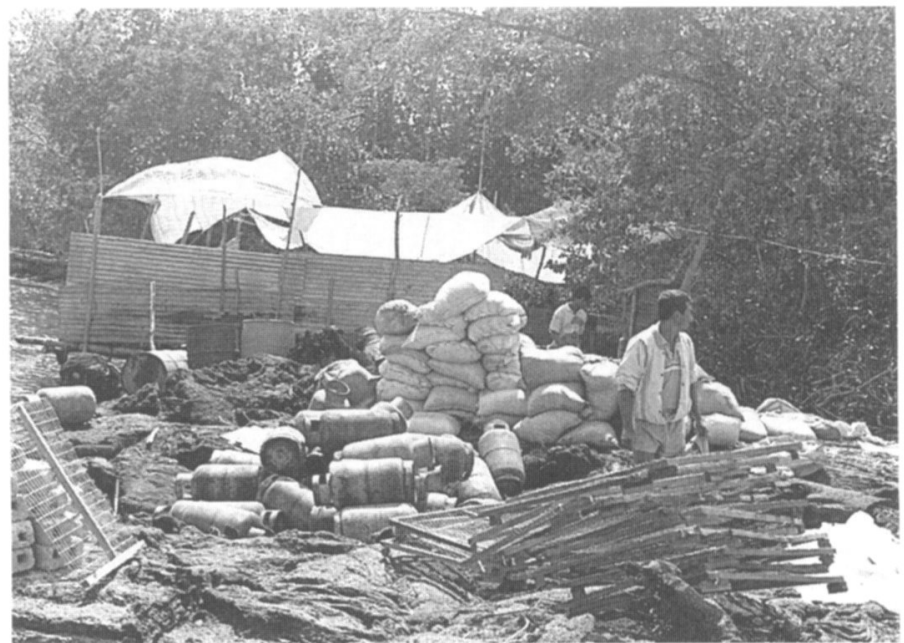

of mainland Ecuador, the sea floor was quickly cleared of sea cucumbers and soon fishermen moved to the western side of Isabela Island and the Bolivar Channel that separates Isabela from Fernandina Island. This narrow stretch of water protects Fernandina, which is one of the very few oceanic islands that remain free from introduced organisms. Its endemic rice rats, Nesoryzomys narboroughi and $N$. fernandinae, still survive, whereas three species of endemic rats became extinct on Isabela after the introduction of European rats Rattus rattus. These two islands also are the only home of two flightless sea birds, the Galâpagos penguin Spheniscus mendiculus and the flightless cormorant Nannopterum harrisi.
It soon became clear that the situation was critical. I, with national park officials and personnel from the Charles Darwin Research Station, investigated these western islands. We found several areas where people had invaded the national park to set up camps to process their catch. Mangrove wood, some alive and some dead, was being used as fuel for cooking the animals. Rubbish lay everywhere and there were perhaps 100 people working in the area. Because of the flagrant breaking of the law, the immediate danger to the ecology of the region, and the chaotic development of the fishery, it was closed by Presidential Decree in August 1992.

From the earliest days of the rowing boats,
Sea cucumbers drying on open lava fields behind the coastal mangroves on the west coast of Isabela Island (Bolivar Channel) (Charles Darwin Research Station).

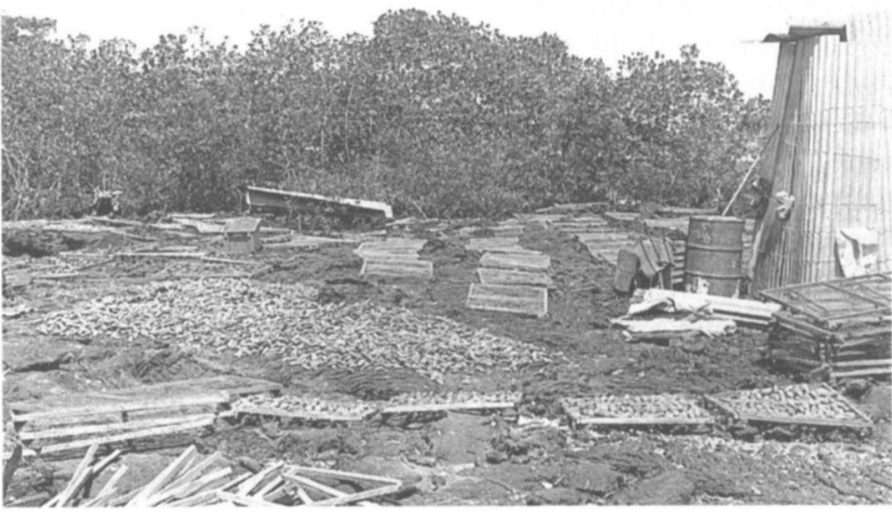




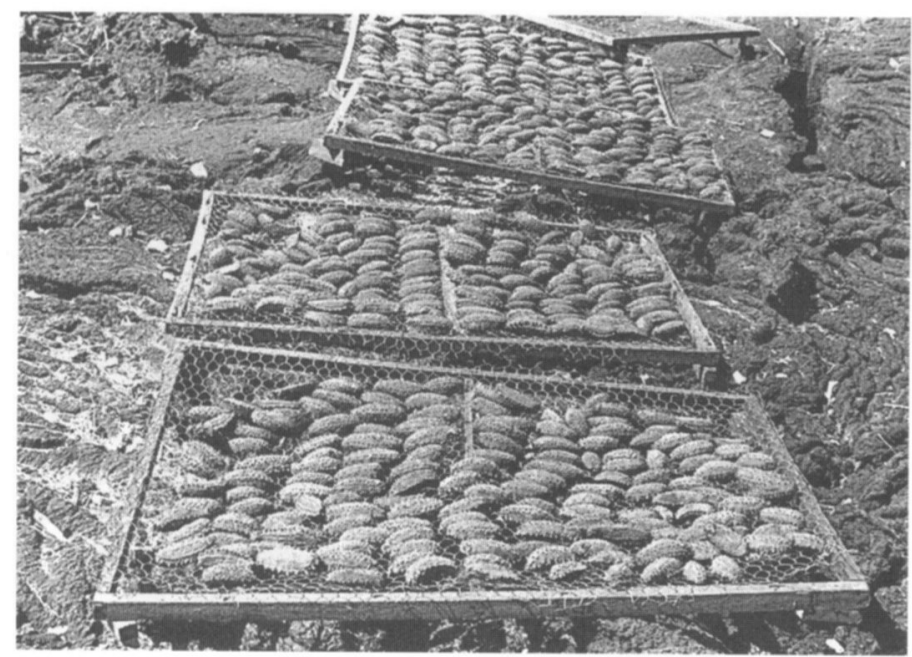

Racks of sea cucumbers drying in the sun after cooking (Charles Darwin Research Station). the fishermen had been accustomed to make camps on the shore. The small size of the boats and the high abundance of the fish made this modus operandi necessary and practical. As fish became fewer, requiring longer periods at sea, and the vessels became larger, the fishermen lived aboard, although still roving the shorelines as beachcombers and using the black lava rocks for drying their catch. However, the recent introduction of small, fast boats and the abundance of a species (sea cucumbers), which, like the bacalao, also must be dried on the black lava rocks, has meant that fishermen have reverted to camping on the shore. Unfortunately for the fishermen, during the intervening years, the national park was established and laws now prohibit the setting up of permanent or transitory camps within the park, which covers 97 per cent of the Galápagos Archipelago.

It is important, however, to realize that, during this period of overwhelming economic forces affecting Galápagos, serious attempts were being made to protect the marine environment. In 1986 the Galápagos Marine Resources Reserve was declared under the Government of León Febres-Cordero. The area granted this title consists of the internal waters of the Archipelago, extending out to lines which connect the extreme points of the Archipelago plus 15 nautical miles. A period of 360 days was allotted to the formulation of regulations and a management plan. However, bureaucratic difficulties delayed this process for several years and it was not until 6 August 1992 that the Management Plan was approved by the Presidential Decree of Rodrigo Borja (Anon., 1992). The Plan clearly defines zones for fishing, the marine national park, tourism, and science.

By the end of 1993, the incidents described below were typical.

1 Tuna vessels were found fishing within 500 $\mathrm{m}$ of the islands, using their massive purse seine nets. At this range, the fishing is highly indiscriminate and all coastal macrofauna is in danger: sea turtles, pinnipeds, non-target fish species, and perhaps even flightless cormorants and penguins. Sharks are often taken in these close-shore operations and may be purposely fished for. These boats are required by law to remain outside the limits of the Resource Reserve.

2 The sea cucumber fishery, although banned, flourished, with new camps being located weekly. In early 1994 tuna boats from Ecuador were implicated in the illegal transport of sea cucumbers gathered during nighttime operations.

3 Sharks were still being trapped. One incident occurred at one of the northernmost islands, Wenman, where a $180-\mathrm{m}$ bottom net was found full of dead hammerhead sharks. This was particularly tragic, because the net 
was so entangled in the corals, which, incidentally, are just recovering from the severe die off after the 1983 El Niño season, that it is extremely unlikely that the fishermen would be able to retrieve their net or profit from the catch. In addition, according to the management plan, this area is under the aegis of Marine National Park zonation.

4 Three large vessels were observed fishing within $5 \mathrm{~km}$ of the east coast of Santa Cruz at night. The largest was estimated at $100 \mathrm{~m}$ or more.

By the Spring of 1994, anarchy prevailed; however, credit must be given to various governmental authorities, who finally began to apply some measure of order by confiscating several cargos of processed sea cucumbers found in vessels that had recently been in Galápagos waters. At the same time, a number of sea cucumbers were confiscated within the Islands themselves. The fishermen were angry and everyone was anxious for the government to make a more positive move.

Currently the main issue for the government is who should profit from Galápagos and at what cost to its natural setting and biology? If the decades of conservation measures and regulations are anything to go by, it appears that the government has accepted the responsibility to see that the Islands' status quo is maintained. Moreover, if all the laws and regulations were applied, there would not be a marine conservation problem. The laws are, however, too often ignored. The situation is critical and clear decisions need to be made with real purpose. If we alter the environment, the changes are often irreversible. If uncontrolled fisheries are permitted within close range of the islands, there simply is no way to know what the effect of disturbance and extraction will be, especially in an area that is well known for its extremely variable marine productivity. Even if the fisheries could be properly controlled, it is still highly questionable whether they should be opened at all, given the poor information available upon which to make judgments. To open a fishery and then close it is probably the worst thing to do, for it will raise expectations and act as a magnet to others, thereby swelling an already large population with high unemployment. The various recent fisheries, apart, perhaps, from the bacalao, have all been subject to overfishing and the use of unacceptable practices of harvesting. They have been outlawed, but the lack of finance and equipment, such as reliable patrol boats, coupled at times with the lack of willpower, has resulted in a lack of respect for the various authorities and a free-forall on the fishing grounds. That a fishing community exists cannot be denied. It need not become extinct, yet it can survive only by strict control of the number of boats, the number of people it can support, and the use of acceptable techniques.

These problems of overfishing, control and employment are not new when looking at fishing on a world scale. The one aspect that is new is the location. It is not just a matter of trying to regulate an unstable fishing community that has never followed regulations, or has had to, but trying to do so while maintaining one of the most valuable natural regions in the world. Some of the fishermen born in the Islands have turned to tourism as an alternative. They operate their own charter boats or crew on them. (It should be remarked that tourism has also swollen the population and caused its own problems, but, as far as the Islands are concerned, the tight control effected by the National Park Service has reduced damage to a minimum.) Now the preservation of their jobs rests on the preservation of Galápagos, but their former companions are still working on the fishing grounds and regard the extractable resources as their right, by birth and economics. The ocean has now become a sea of conflict for these fishermen and the situation has been made more volatile by an invasion of quick-profit opportunists from the mainland who know nothing about Gálapagos. There is doubt, conflict, and jealousy in a world of escalating prices. There is an urgent need for a compassionate but firm guidance. The first priority has to be Galápagos, now and tomorrow, natural, native, and respected. 


\section{Acknowledgements}

Most of the information in this manuscript was gathered through friends or from my own recollections. Particular thanks are paid to Carmen Angermeyer, who arrived in the Galápagos Islands in the 1930s, and to Leonardo Andrade, who was born into a fishing family on San Cristobal in 1943. I would also like to acknowledge the helpful comments from two anonymous referees.

\section{References}

Anon. 1992. Plan de Manejo de la Reserva de Recursos Marinos de Galápagos. Comisión Permanente para las Islas Galápagos. Quito, Ecuador.

Reck, G.K. 1983. The coastal fisheries in the Galápagos Islands. Dissertation Christian-Albrechts University, Kiel, Bremerhaven.

Sommerville, W.S. 1993. Marketing of beche-de-mer. Beche-de-Mer Information Bulletin No. 5: 2-4. (South Pacific Commission, Marine Resources Programme, Fisheries Information Project)

Wellington, G.M. 1975. The Galápagos Coastal Marine Environments. Report to the Department of National Parks and Wildlife, Quito, Ecuador. Unpubl. manuscript.

\section{Postscript}

On 23 June 1994, in the capital of the province, Puerto Baquerizo Moreno, on San Cristobal Island, the National Fishery Development Board finally decided on a plan for the future of fishery activity in the Islands. A pilot plan was brought into action, which, in the first instance, has a duration of 1 year. This plan allows for fishing of sea cucumbers, sharks, and lobsters, each for 3 months. Bottom-fishing for whitefish remains without time limit. There are 53 points (with latitude and longitude given), each surrounded by a zone of 1 mile, that are called marine sanctuaries for diving and tourism. Fishing is not allowed within these zones. Tourist boats are forbidden from fishing any species and must buy from local fishermen in one of the ports. Sea cucumbers, shark products (fins and skin), and lobsters are all permitted to be exported. Sea cucum- bers have a year limit of 550,000 individuals and must be processed in the villages. Lobsters have unlimited catch for consumption within the Archipelago and an export limit 10 tons. Shark fishing has no limit. The fishing for sharks will be permitted 3 miles ( 5 $\mathrm{km}$ ) offshore with the use of long lines. Fishing may only be carried out by members of the three fishing co-operatives, and their members must have residency in Galápagos for 5 years.

The new regulation has certain positive attributes, but there are grave reservations. The regulations were to come into effect in July 1994. At the time of writing there was no infrastructure in place to control this complicated system. The administration is divided between the National Park Service and the Fisheries Department. The work will fall largely on the Park Service, because the Fisheries Department has no administrative centre in the Islands. I believe that the Park Service has real intentions to fulfil their obligations, but, apart from the bureaucratic side, there is the practical side to consider. These fisheries have been opened with no long-term research that might indicate trends in populations of the species to be exploited. Moreover, the lack of stability in oceanic conditions which surround the Islands makes short-term studies unreliable as management tools. The side effects of fishing and tourist activities on fragile species such as the endemic Galápagos penguin are totally unknown.

Although there is the livelihood of the fishermen to consider, there is now not one inch of coastline that is not dedicated either to fishing or tourism. It does seem that the Islands have finally come under the exclusive domain of economics. This dedication to economic development is incompatible with the concept, so widely used in referring to Galápagos, of a living natural laboratory. We will, most probably, never now know the effects of meddling in this unique marine environment.

Godfrey Merlen, PO Box 2542, Quito, Ecuador. 